\title{
LEY APLICABLE A LA FILIACIÓN POR NATURALEZA: DE LA LEY NACIONAL A LA LEY DE LA RESIDENCIA HABITUAL DEL HIJO
}

\author{
Javier CARRAscosa GonZÁLEZ*
}

SUMARIO: 1. LEY APLICABLE A LA FILIACIÓN EN DERECHO INTERNACIONAL PRIVADO ESPAÑOL. LA ENCRUCIJADA VALORATIVA.-1.1. Introducción.-1.2. El art. 9.4, párr. 1. ${ }^{\circ}$ del CC, en su redacción de 2015.-1.3. Ausencia de regulación conflictual de la filiación en el Derecho de la Unión Europea.-2. LAS CONEXIONES.-2.1. Primera conexión. Residencia habitual del hijo. Análisis valorativo.-2.2. Segunda conexión. La nacionalidad del hijo. Análisis valorativo.-2.3. Tercera conexión. Conexión judicial: ley española.-3. LA ORIENTACIÓN MATERIAL DEL ART. 9.4.I CC.-3.1. Contenido del Derecho aplicable y resultado de la aplicación del Derecho extranjero.-3.2. La "paradoja conflictual circular».-3.3. Motivos que impiden establecer la filiación.-3.4. Análisis crítico de la orientación material del art. 9.4.I CC.-4. REFLEXIÓN FINAL.

\section{LEY APLICABLE A LA FILIACIÓN EN DERECHO INTERNACIONAL PRIVADO ESPAÑOL. LA ENCRUCIJADA VALORATIVA}

\subsection{Introducción}

1. La precisión de la ley aplicable a la filiación por naturaleza en los casos internacionales ha sido siempre una cuestión particularmente complicada debido a varios factores ${ }^{1}$.

\footnotetext{
* Catedrático de Derecho internacional privado en la Universidad de Murcia (carras@um.es). Doctor en Derecho por la Universidad de Bolonia (1991). Profesor en la Academia de La Haya de Derecho internacional (julio 2015). Representante de España en la negociación del Reglamento «Roma III». Autor de ocho monografías relativas al Derecho internacional privado, y de un manual de Derecho internacional privado español en dos volúmenes (junto con el Prof. Dr. D. A.-L. CaLvo CARAvacA) (16. ${ }^{a}$ ed.), Granada, 2016. Ha publicado trabajos de investigación jurídica en España, Alemania, Gran Bretaña, Italia, Portugal, Francia, Estados Unidos, Argentina, Méjico, Colombia, Chile y Uruguay.

1 Véanse inter alia, GonzÁlez CAmpos, J. D., "Filiación», en González CAmpos et al., Derecho internacional privado, parte especial, Madrid, Eurolex, 1995, pp. 355-376; id., "Arts. 9.4 y 5 CC», Comentarios al Código civil del Ministerio de Justicia, Madrid, 1991, pp. 84-90; RoDríguez Benot, A., «La filiación y los alimentos», en Aguilar Benítez De Lugo, M. et al., Lecciones de Derecho civil internacional, Madrid, Tecnos, 1996, pp. 172-206; Álvarez González, S., "Art. 9.4 CC», en Albaladejo, M. y Díaz Alabart, S.
} 
En primer lugar, se aprecia la tensión de un innegable y crudo «conflicto de civilizaciones» que se produce porque los distintos Derechos nacionales ordenan jurídicamente la filiación de modos muy diferentes, frecuentemente opuestos. El art. 9.4 del Código $\mathrm{Civil}^{2}$ (en adelante, CC) debe ser estudiado desde el ángulo de su potencialidad para resolver, de un modo conciliador, como han sugerido A. Yokaris y M.-P. Weller, un conflicto de civilizaciones producto de la diversidad cultural que se refleja en las normas jurídicas que regulan la filiación en cada Estado y en cada sociedad ${ }^{3}$.

En segundo lugar, la inmensa mayoría de los Estados occidentales han acogido un enfoque intervencionista y publicista en la regulación de la filiación. En la actualidad, los poderes públicos entienden que la filiación es un sector en el que se hallan implicados no solo intereses particulares, sino intereses generales, de toda la sociedad. Esta diagonal fulgurante que penetra con fuerza en la solución de los conflictos de leyes, representada por los «intereses generales», supone que la determinación de la ley aplicable a la filiación debe tener presentes no solo los intereses de los particulares implicados, sino los intereses generales de la sociedad y en particular, de la infancia y de la adolescencia. En este sentido, expone M. Virgós Soriano que la evolución del Derecho sustantivo en el sector de la filiación ha sido, en los Estados europeos y en particular en España, extraordinariamente intensa desde el punto de vista axiológico. Nuevos valores han cambiado totalmente el régimen jurídico material de la filiación por naturaleza. Se han eliminado las diferencias hirientes y discriminatorias entre distintas «clases de hijos» — como los adulterinos, naturales, espurios, etc.—, se ha colocado el principio de verdad biológica de la filiación como punto central del sistema, se ha potenciado el derecho a una familia real y a una filiación verdadera, y se han dejado atrás ideas ya superadas como la protección del honor de la familia, la dominación de la familia por el padre-marido y otras similares, radicalmente incompatibles con la Constitución Española de 1978 y con la normativa internacional que regula los derechos humanos ${ }^{4}$. Esta evolución material y valorativa del Derecho de la filiación presenta un profundo impacto en la determinación de la ley aplicable a la filiación.

2. La anterior regulación relativa a la ley aplicable a la filiación, que databa de 1996, presentaba, en efecto, varias fallas tanto técnicas como valorativas, muy bien descritas por L. F. Carrillo Pozo ${ }^{5}$. Como denunciara con pleno acierto M. Guzmán Zapater, el art. 9.4 CC, versión de 1974 y versión de 1996, deter-

(dirs.), Comentarios al Código Civil y a las Compilaciones forales, t. I, vol. 2, Madrid, 2. ${ }^{a}$ ed., Ed. Revista de Derecho privado/Edersa, 1995, pp. 205-242; GuZMÁn ZAPATER, M., El derecho a la investigación de la paternidad, Civitas, 1996; RuIz SutiL, C., Filiación Hispano-Marroquí. La situación del nacido en España de progenitor marroqui, 2011.

2 Gaceta de 25 de julio de 1889.

3 YoKARIS, A., "Le droit international face au défi de la diversité culturelle», Revue hellénique de droit international, 2009-I, pp. 695-704; WELLER, M.-P., «Die neue Mobilitätsanknüpfung im Internationalen Familienrecht - Abfederung des Personalstatutenwechsels über die Datumtheorie», IPRax, 2014-3, pp. 225-233.

4 Virgós Soriano, M., «Nota a la DGRN de 10 de enero de 1984», REDI, 1984, pp. 670-674.

5 CARrillo Pozo, L. F., «La filiation dans le droit international privé espagnol: quelques profils critiques», RDIPP, 1995, pp. 585-606. 
minaban la ley aplicable a la filiación de un modo ciego, sin tener presente ni el contenido de la ley aplicable, ni el resultado al que conducía la aplicación de dicha ley al caso concreto, lo que constituía una carencia axiológica cuanto menos llamativa ${ }^{6}$. La Ley $26 / 2015$, de 28 de julio, de modificación del sistema de protección a la infancia y a la adolescencia ${ }^{7}$, ha dado nueva redacción al art. 9.4 CC y ha introducido, de modo inconcuso, valores materiales (favor filii) en la selección del Derecho aplicable al establecimiento de la filiación.

3. El art. 2 de la Ley $26 / 2015$, de 28 de julio, de modificación del sistema de protección a la infancia y a la adolescencia ha dado nueva redacción al art. 9.4 CC. Este precepto determina la ley aplicable a la filiación por naturaleza en DIPr español. El art. 9.4 CC actual se presenta dividido en dos partes que se ocupan de cuestiones diferentes. En primer lugar, se fija la ley reguladora de la determinación y el carácter de la filiación por naturaleza mediante una norma de conflicto con tres puntos de conexión estructurados de modo jerárquico o en cascada (art. 9.4.I CC). En segundo término, se precisa la ley reguladora del contenido de la filiación, por naturaleza o por adopción, y también la ley aplicable al ejercicio de la responsabilidad parental (art. 9.4.II CC) y ello se hace mediante una norma de remisión al Convenio de La Haya de 19 de octubre de 1996 (responsabilidad parental y protección de niños). Son las normas de conflicto contenidas en este convenio las que determinan la ley reguladora de las instituciones jurídicas de protección de los menores y la ley reguladora del ejercicio de la responsabilidad parental que se ejercita a través de dichas instituciones.

4. En el presente trabajo se realizan unas breves consideraciones sobre la estructura del art. 9.4.I CC y sobre las conexiones empleadas por el precepto, de las que se realizará un análisis exclusivamente valorativo y no técnico. Quedarán al margen, igualmente, y por razones de espacio, otras cuestiones, como el ámbito de la ley reguladora de la filiación por naturaleza, los aspectos relativos a la filiación derivados de la llamada "gestación por sustitución», los perfiles de Derecho interregional, así como las instituciones de protección de menores y el régimen jurídico de la responsabilidad parental en casos internacionales y los problemas de aplicación propios de la norma de conflicto.

\subsection{El art. 9.4, párr. $10^{\circ}$ del $\mathrm{CC}$, en su redacción de 2015}

5. El art. 9.4.I CC es una norma de conflicto multilateral que fija la ley aplicable a la determinación y al carácter de la filiación por naturaleza. Ese es el objeto regulado. A tal efecto, la norma emplea varios puntos de conexión. El primero de ellos es la «residencia habitual del hijo». De este modo, la determinación y el carácter de la filiación por naturaleza se regirán por la ley de la residencia habitual del hijo en el momento del establecimiento de la filiación. El segundo punto de conexión es la nacionalidad del hijo. Así, se aplicará la ley nacional del hijo en el momento del establecimiento de la filia-

\footnotetext{
${ }^{6}$ GuZmán Zapater, M., El derecho a la investigación de la paternidad, Civitas, 1996, pp. 33-37.

7 BOE núm. 180, de 29 de julio de 2015.
} 
ción en estos dos casos: a) si el hijo careciere de residencia habitual, y b) si la ley de la residencia habitual del hijo no permitiere el establecimiento de la filiación. En tercer lugar, por último, precisa el art. 9.4.I in fine CC que se aplicará la ley sustantiva española en estos dos supuestos: $a$ ) si la ley nacional del hijo no permitiere el establecimiento de la filiación, y b) si el hijo careciere de residencia habitual y de nacionalidad.

6. Dos ideas fuerza relativas al art. 9.4.I CC resultan ahora importantes para comprender el alcance de la nueva redacción de este precepto. En primer lugar, debe subrayarse que el art. 9.4.I CC recoge, como se ha visto, diversos puntos de conexión estructurados en modo subsidiario o en cascada que resultan aplicables unos en defecto de otros. En segundo término, el precepto citado es una norma de conflicto materialmente orientada que apunta a la aplicación de la ley de la residencia habitual del hijo pero que ordena también no aplicarla en el caso de que dicha ley no permita el establecimiento de la filiación del hijo en el caso concreto. En dicho supuesto, se aplicará la ley nacional del hijo y si esta tampoco permite el establecimiento de la filiación del hijo, se aplicará la ley sustantiva española.

\subsection{Ausencia de regulación conflictual de la filiación en el Derecho de la Unión Europea}

7. El Derecho internacional privado de la Unión Europea (UE) carece de normas de conflicto que señalen la ley aplicable a la filiación. Esta ausencia tiene una explicación clara que arranca de un dato bien conocido: con arreglo a normas consuetudinarias de Derecho internacional público, cada Estado dispone de la competencia exclusiva de concretar quiénes son sus nacionales. A partir de dicho dato, la UE ha activado dos líneas de política jurídica perfectamente definidas.

La primera línea de política jurídica consiste en admitir y respetar esa competencia exclusiva de los Estados miembros para determinar qué personas físicas ostentan la nacionalidad de cada Estado miembro. La jurisprudencia del TJUE ha seguido con total transparencia, a pesar de ciertos matices que imponen el respeto a los principios fundamentales del Derecho de la UE, esta primera línea [as. C-369/90, ECLI:EU:C:1992:295, FFJJ 10-11 (doble nacional italo-argentino con residencia habitual en España); as. C-122/96, ECLI:EU:C:1997:458 (ciudadano norteamericano y británico); as. C-179/98, ECLI:EU:C:1999:549, FJ 29; as. C-168/08, ECLI:EU:C:2009:474 (dobles nacionales franco-húngaros); as. C-135/08, ECLI:EU:C:2010:104, FFJJ 39, 45 (sujeto austríaco que deviene alemán y pierde posteriormente la nacionalidad alemana y resulta apátrida); as. C-200/02, ECLI:EU:C:2004:639; as. C-274/96, ECLI:EU:C:1998:563, FJ 17; as. C-148/02, ECLI:EU:C:2003:539, FJ 25; as. C-403/03, ECLI:EU:C:2005:446, FJ 19; as. C-145/04, ECLI:EU:C:2006:543, FJ 78] .

\footnotetext{
8 Jurisprudencia analizada en Calvo Caravaca, A. L. y CARrascosa González, J., «Persona física», en Derecho internacional privado, vol. 2, 16. ${ }^{\text {a }}$ ed., Granada, Comares, 2016, pp. 39-50.
} 
La segunda línea de política jurídica seguida por la UE en este sector ha sido la activación del llamado "principio del mutuo reconocimiento». La competencia exclusiva de cada Estado miembro para determinar quiénes son sus nacionales constituye una plataforma teórica muy poderosa para afirmar que es ese mismo Estado el que debe definir quiénes son "personas» en su sistema legal y los atributos jurídicos esenciales de las mismas. Esa idea, anclada en argumentos de Soberanía, explica por qué el DIPr de la UE ha renunciado a elaborar Reglamentos que determinen la ley aplicable a las cuestiones que afectan directamente a la personalidad de la persona física, su nombre y apellidos, su capacidad, su estado civil, y su filiación, incluida la adoptiva. Tales materias, muy vinculadas a la persona, se dejan en manos de los Estados miembros. De ese modo, cada Estado miembro fija la ley reguladora de estos extremos de manera independiente los unos de los otros. La UE respeta así la soberanía de cada Estado miembro, la competencia exclusiva de cada Estado miembro para determinar qué personas ostentan su nacionalidad y también, por derivación, la competencia exclusiva de cada Estado miembro para especificar la ley estatal aplicable a las cualidades personales de cada individuo: su nombre, capacidad, estado civil y filiación. Por tanto, en relación con el estatuto personal, la UE ha preferido adoptar un «enfoque conflictual integrador» y no un «enfoque conflictual normativo». Es decir, la UE no ha elaborado normas de conflicto que señalan la ley aplicable a las materias integradas en el estatuto personal, entre ellas la filiación (= enfoque integrador normativo), sino que ha empleado la técnica del «mutuo reconocimiento» de situaciones jurídicas relativas a la persona (= enfoque integrador por reconocimiento). De ese modo, por ejemplo, cada Estado miembro fija, con arreglo a sus normas de conflicto nacionales, la ley aplicable al nombre de la persona física y los demás Estados miembros están obligados, por el Derecho de la UE, a aceptar las situaciones jurídicas creadas válidamente por otros Estados miembros con arreglo a tales normas de conflicto, sea cual fuere el punto de conexión empleado por estas. El nombre de un niño alemán impuesto por las autoridades danesas con arreglo a la ley del domicilio del niño, que es el punto de conexión utilizado por la norma de conflicto danesa que fija la ley aplicable al nombre de la persona física, debe ser reconocido en Alemania y en los demás Estados miembros. De este modo, cada Estado miembro conserva sus propias normas de conflicto nacionales, con sus propios puntos de conexión, para determinar la ley reguladora de las cualidades de la persona, incluida la filiación natural y la adoptiva (véase en el ámbito del nombre de la persona física: as. C-168/91, ECLI:EU:C:1993:115; as. C-148/02, ECLI:EU:C:2003:539; as. C-353/06, ECLI:EU:C:2008:559; as. C-208/09, ECLI:EU:C:2010:806; as. C-391/09, ECLI:EU:C:2011:291). Además, el mutuo reconocimiento en los Estados miembros de la UE de la filiación establecida en otro Estado miembro garantiza la libre circulación de personas (art. 21 del Tratado de Funcionamiento de la Unión Europea) y asegura también el respeto de la familia, de la vida familiar y de la vida privada de los sujetos cuya filiación ha quedado acreditada en un concreto Estado miembro, en sintonía, precisan A. Dionisi-Peyrusse y C. F. Nordmeier, con el art. 8 
del Convenio Europeo de Derechos Humanos (CEDH $)^{9}$. Lo anterior permite explicar la actual ausencia de normas de conflicto europeas en el sector de la filiación. Esta situación comporta que no exista un «punto de conexión europeo» relativo a la filiación por naturaleza, como tampoco existe un "punto de conexión europeo» en el sector de la capacidad civil, el nombre de la persona, la filiación adoptiva, o el estado civil en general. De ese modo, los Estados miembros conservan su competencia para elaborar las normas de conflicto que deseen en orden a concretar la ley reguladora de la filiación y demás materias integradas en el tradicional «estatuto personal». Se crea, así, un «Derecho internacional privado jerarquizado» compuesto por diferentes niveles regulativos, el europeo y el nacional-español, que funciona, apunta J.-S. Bergé, de modo armónico en la construcción del espacio judicial europeo ${ }^{10}$.

\section{LAS CONEXIONES}

\subsection{Primera conexión. Residencia habitual del hijo. Análisis valorativo}

8. En la actualidad, España es un país receptor de menores extranjeros. Los litigios internacionales sobre filiación son frecuentes y suelen afectar a menores extranjeros. La opción del legislador español ha sido realista. Hasta 2015, con el texto del art. 9.4 CC (versión de 1996) los tribunales españoles se veían obligados a aplicar leyes extranjeras sobre filiación si el hijo ostentaba una nacionalidad extranjera. El legislador español ha considerado que la residencia habitual es una conexión realista, que responde a la situación actual de España como país receptor de personas con nacionalidad extranjera, no solo «inmigrantes económicos». La opción tomada por el legislador español es acertada. La residencia habitual del hijo constituye la mejor conexión en el sector de la filiación y ello se explica por varias razones.

9. En primer lugar, la residencia habitual del hijo es una "conexión social». Refleja el vínculo de la persona con la sociedad en la que dicha persona se halla integrada a un nivel de «relaciones fácticas» (= es el ambiente relacional del hijo). El legislador español ha dado así un poderoso giro, casi más que copernicano, al sistema español de normas de conflicto en las materias relativas al tradicional estatuto personal y familiar. Como han señalado F. Rigaux y M. Fallon, la "conexión cultural» (= "proximité culturelle»), representada por la nacionalidad de la persona, deja paso, lenta pero inexorablemente, a la «conexión social» (= «proximité social»), representada por la residencia

\footnotetext{
9 Dionisi-Peyrusse, A., «La conformité à l'article 8 de la CEDH des refus de reconnaissance des situations familiales crées à l'étranger au nom de l'ordre public international», en Mélanges à la mémoire de Patrick Courbe, 2012, pp. 157-177; NordMEIER, C. F., «Stand, Perspektiven und Grenzen der Rechtslagenanerkennung im europäischen Rechtsraum anhand Entscheidungen mitgliedstaatlicher Gerichte», IPRax, 2012, núm. I, pp. 31-39.

10 BERgé, J.-S., «De la hiérarchie des normes au droit hiérarchisé: figures pratiques de l'application du droit à différents niveaux», JDI Clunet, 2013, núm. 1, pp. 3-25.
} 
habitual de la persona ${ }^{11}$. El punto de conexión «residencia habitual del hijo» se apoya sobre bases valorativas poderosas que explican por qué ocupa, en el art. 9.4.I CC, el escalón más alto de la escalera conflictual en el sector de la filiación por naturaleza. En condiciones normales, la residencia habitual del hijo siempre refleja una conexión auténtica, real, verdadera y sustancial con dicho país. El valor conflictual de la conexión "residencia habitual del hijo» es más sólido y firme que el valor conflictual de la conexión «nacionalidad». En efecto, la conexión «nacionalidad» puede quedar reducida a un vínculo meramente formal y aparente, mientras que la conexión «residencia habitual» constituye siempre una conexión sustancial de la persona con el país en cuya sociedad se halla integrado. Ello explica, advierte M.-P. Weller, la progresiva pero imparable sustitución de la nacionalidad en favor de la residencia habitual tanto en el DIPr europeo como en el DIPr español ${ }^{12}$.

10. En segundo lugar, esta conexión comporta costes conflictuales reducidos para las partes implicadas. El país donde el hijo tiene su residencia habitual en el momento de la interposición de la demanda es el país donde se encuentra el «centro social de vida» del hijo. Es el país donde dicho sujeto se relaciona habitualmente con terceros, es el país donde normalmente reside también el núcleo de su familia, donde el hijo suele estar integrado en un entorno laboral y patrimonial. Por ello, la residencia habitual del hijo es una «conexión social» (= el hijo está vinculado con un Estado porque participa en la sociedad de ese Estado). El legislador español entiende que la «conexión social» conduce a una ley que genera costes conflictuales menores que los que comporta la aplicación de la ley estatal a la que conduce una "conexión cultural», como es la nacionalidad del hijo. Es decir, el legislador español ha preferido la residencia habitual del hijo como punto de conexión porque arranca de la idea de que las partes en un proceso de filiación conocen mejor o se encuentran en una situación en la que pueden conocer mejor, y, por tanto, a un coste más reducido, la ley del país de la residencia habitual del hijo, que la ley de cualquier otro Estado, incluida la ley del país de la nacionalidad del hijo en el momento de presentación de la demanda. La ley del país de la residencia habitual del hijo en el momento de la interposición de la demanda es una ley de «aplicación previsible» para las partes. Puede presumirse que las partes en un litigio de filiación conocen o están en posición óptima para conocer el Derecho del país de la residencia habitual del hijo. Debe tenerse presente, además, que la residencia habitual del hijo constituye un factor externo ( $=$ un elemento fácilmente perceptible por terceros). Todos estos pueden averiguar, a un coste reducido y razonable, cuál es la ley del país de la residencia habitual del hijo. En definitiva, la ley del país donde se encuentra la residencia habitual del hijo es la ley estatal que permite resolver el litigio de filiación a un coste jurídico-conflictual más reducido para las partes.

En principio, y desde el punto de vista conflictual, la calidad de la vinculación que representa el punto de conexión «residencia habitual del hijo» es

\footnotetext{
11 Rigaux, F. y Fallon, M., Droit international privé, 3. a ed., Bruselas, 2005, pp. 572-578.

12 Weller, M.-P., op. cit., nota 3, pp. 225-233.
} 
superior a la calidad de la vinculación propia de la conexión «nacionalidad del hijo». Ello se explica porque la residencia habitual está basada, necesariamente, en "contactos sustanciales» del hijo con un país (= es el país donde, efectivamente, el hijo vive y habita, el país en cuya sociedad se haya integrado el hijo), mientras que la «nacionalidad» es un punto de conexión basado en contactos que pueden ser puramente «formales» o «meramente aparentes» (= se puede ostentar la nacionalidad de un país sin haber vivido jamás en dicho país o habiendo abandonado dicho país hace años). La residencia habitual representa, por ello, en los litigios de filiación, la conexión «más real y sustancial» de una situación con un concreto Estado, como ha subrayado la más acreditada doctrina ${ }^{13}$. La nacionalidad se ostenta, pero en la residencia habitual se vive.

El fundamento de la conexión «residencia habitual del hijo» reviste, por tanto, en esencia, un carácter económico y está alejada de elementos relacionados con la Soberanía del Estado. En efecto, la aplicación de la ley de la residencia habitual del hijo es una solución eficiente, porque, en términos generales, dicha ley comporta los costes conflictuales más reducidos para las partes (= solventa el litigio de filiación al coste más reducido para los litigantes). Desde este punto de vista, el art. 9.4.I CC (conexión primera) declara la aplicación de la ley del país de la residencia habitual del hijo pero no por motivos de soberanía. No se trata de aplicar la ley del país de la residencia habitual del hijo como homenaje a la soberanía del Estado en cuyo territorio el hijo reside habitualmente. Se trata de resolver la cuestión de la filiación al menor coste global para las partes (= es la solución conflictual más eficiente). La precisión de la filiación de un menor argelino con residencia habitual en Palencia no afecta a la soberanía española ni a los intereses del Estado español. Es una cuestión que afecta, por el contrario, a los intereses del hijo y de otros particulares (= personas físicas, sujetos individuales de Derecho). Por ello la cuestión debe resolverse con atención a tales intereses privados mediante la aplicación de la ley estatal que les comporta los costes más reducidos.

11. En tercer lugar, debe recordarse que la sociedad actual se caracteriza por su extrema movilidad y su marcado carácter líquido (= una sociedad líquida en la que las relaciones personales, territoriales y culturales son flexibles, temporales y efímeras). Las personas cambian, con extrema facilidad, de país de residencia habitual, de trabajo, de cultura y de familia. Este punto de conexión permite, en sintonía con lo anterior, la movilidad de la ley aplicable y la aplicación de la ley que responde al ambiente social actual del hijo (= es una «conexión de presente»). A una sociedad líquida como la actual

13 Henrich, D., «Family Law Across Frontiers: Facts, Conflicts, Trends», en LowE, N. y DougLAS, G. (eds.), Families Across Frontiers, La Haya, 1996, pp. 41-51; DE BoER, Th. M., "Prospects for European Conflicts Law in the Twenty-First Century», en BorCHERs y ZEKOLL (eds.), International Conflict of Laws for the Third Millennium, Essays in Honor of F. K. Juenger, Nueva York, Transnational Publishers/Ardsley, 2001, pp. 193-214; McElEAVy, P., «The Brussels II Regulation: how the European Community has moved into Family Law», ICLQ, vol. 51, octubre de 2002, pp. 883-908. 
caracterizada por una movilidad estructural y creciente debe corresponder una conexión también líquida y movible. De ese modo, igual que es sencillo cambiar de país de residencia y trabajo debe ser también fácil cambiar de ley aplicable a la filiación. La residencia habitual, enfatiza M.-P. Weller, es una conexión que alcanza perfectamente dicho objetivo ${ }^{14}$. La nacionalidad, como es sabido, es un punto de conexión muy rígido. La pérdida y adquisición de la nacionalidad siguen procedimientos jurídicos muy estrictos, que requieren mucho tiempo y que no reflejan adecuadamente la movilidad de las personas, propia del momento presente en el contexto de una sociedad líquida.

12. En cuarto lugar, la ley del país de la residencia habitual del hijo proporciona una aceptable estabilidad jurídica al estado civil del hijo. En efecto, la ley aplicable no cambia por el hecho de que el hijo traslade a otro país su «residencia de hecho», ni por el hecho de que cambie de nacionalidad o realice un viaje o una estancia, más o menos prolongado, a otro país o de que se traslade temporalmente a otro país por motivos de trabajo, estudio, por cuestiones médicas, vacacionales o similares. Es cierto que este punto de conexión, debido precisamente a la extrema movilidad internacional actual que presentan las familias, puede amenazar, en ocasiones, la estabilidad de la ley aplicable. Ahora bien, el relieve de esta crítica no debe exagerarse. El cambio de país de residencia habitual del hijo significa que existe «otra sociedad» en la que el hijo se halla integrado, por lo que es justo que se aplique dicha ley (= que comportará menores costes conflictuales a todos los implicados). Un viaje a otro país no comportará un cambio de la ley aplicable porque la residencia habitual no se adquiere por la mera «presencia» o la mera «estancia» en un concreto país.

13. En quinto lugar, este punto de conexión garantiza el efecto útil de la función ordenadora del Derecho sobre la sociedad. Los Estados legislan para ordenar «su sociedad» de un modo concreto, también en los sectores más clásicos del Derecho privado, como la filiación por naturaleza. Como ha subrayado G. P. Romano, este punto de conexión permite al Estado realizar, en relación con la inmensa mayoría de la población que habita en su territorio, los objetivos que persigue su ordenamiento jurídico en lo relativo al Derecho de la persona y familia y, en concreto, en lo que afecta a la filiación ${ }^{15}$. Las leyes se hacen para los presentes, no para los ausentes. Aunque este punto de conexión ha sido criticado, en ocasiones, por suponer una asimilación a la fuerza de los inmigrantes que residen habitualmente en países occidentales, una suerte de «etnocentrismo legal», explica J. Schacherreiter, la crítica no debe exagerarse ${ }^{16}$. En realidad, la aplicación de la ley de la residencia

\footnotetext{
14 Weller, M.-P. «Anknüpfungsprinzipien im Europäischen Kollisionsrecht: Abschied von der "klassischen" IPR-Dogmatik?», IPRax, 2011-V, pp. 429-436; id., op. cit., nota 3, pp. 225-233.

15 Romano, G. P., «La bilateralité éclipsée par l'autorité. Développements récents en matière d'état des personne», RCDIP, 2006, pp. 457-520.

16 Schacherreiter, J., «Das Verhängnis von Ethnozentrismus und Kulturrelativismus in der Rechtsvergleichung - Ursachen, Ausprägungsformen und Strategien zur Überwindung», RabelsZ, 2013, pp. 272-299.
} 
habitual del hijo no pretende imponer por la fuerza un régimen legal a los extranjeros que residen en un concreto país. Se trata de reforzar la previsibilidad de la ley aplicable para los particulares y de garantizar la efectividad del régimen jurídico de la filiación en la sociedad del país donde los hijos residen. La regulación de la filiación no es un asunto meramente privado que las partes puedan regular a su libre albedrío. La regulación jurídica de la filiación constituye una legislación de profundo carácter social. Es Derecho privado institucional, en la famosa dicción de P. H. Neuhaus, y por eso es Derecho imperativo ${ }^{17}$. Ello explica que la precisión de la ley aplicable a la filiación no deba dejarse a la libre elección de ley por los particulares.

\subsection{Segunda conexión. La nacionalidad del hijo. Análisis valorativo}

14. La ley del país cuya nacionalidad ostenta el hijo encuentra aplicación en dos supuestos. En primer lugar, cuando el hijo carece de residencia habitual en un concreto Estado. En segundo lugar, cuando la ley del país donde este tiene su residencia habitual «no permitiere el establecimiento de la filiación».

15. El art. 9.4.I CC, segundo punto de conexión, opta por la aplicación de la ley «nacional» del hijo y no por la aplicación de la ley «personal» del hijo. Esta decisión de política legislativa es adecuada y refleja un clarísimo y muy relevante cambio de tendencia. En el sistema español de normas de conflicto diseñado en 1974, la «ley personal» de las personas físicas era la «ley nacional» de las mismas, como todavía hoy indica la letra del art. 9.1 CC y como había señalado la práctica registral en el sector de la filiación. Sin embargo, en la actualidad, y diga lo que diga el texto del art. 9.1 CC, que permanece inalterado desde 1974, esta equivalencia entre «ley personal» y «ley nacional» no está en absoluto clara y es, incluso, más que discutible. Numerosas situaciones privadas internacionales que afectan a la persona se rigen en la actualidad por una ley que no es la ley nacional de la persona. Así puede apreciarse en este mismo art. 9.4 CC y también en el art. 9.6 CC, que entienden que la ley de la residencia habitual de la persona prevalece sobre la ley de su nacionalidad en sectores relativos al tradicional «estatuto personal» del individuo. Por tanto, la ley personal de las personas físicas ya no es necesariamente su ley nacional. En consecuencia, el art. 9.4.I CC ha hecho bien en declarar la aplicación, como segundo punto de conexión de la norma, de la ley «nacional» y no de la ley «personal» del hijo. La aplicación a la filiación por naturaleza de la ley nacional del hijo como segundo punto de conexión en el art. 9.4.I CC suscita algunas reflexiones ahora desde el prisma axiológico que sirven para ponderar las ventajas operativas de dicha conexión y el significado profundo de la misma en el esquema conflictual del art. 9.4.I CC.

17 Neuhaus, P. H., «Prinzipien oder Interessen als Basis des internationalen Privatrechts?», en Homenaje Petros G. Vallindas, Thessaloniki, 1974, pp. 549-557. 
16. En primer lugar, ciertas familias de emigrantes se encuentran en un país de manera no habitual y/o no estable pero tienen la intención de regresar, más pronto o más tarde, a sus países de origen o tienen la intención de cambiar de país de residencia habitual. En tales supuestos, en los que el hijo no tiene residencia habitual en un país concreto, la aplicación de la ley nacional del hijo suscita costes conflictuales reducidos para todos los implicados en los procesos de filiación. Con frecuencia, en defecto de residencia habitual del hijo, la nacionalidad del mismo es la mejor conexión posible. Estas familias se hallan fuertemente conectadas con sus países de origen, observan las costumbres de tales países y conocen sus leyes nacionales con una aceptable precisión. En tales supuestos, la ley nacional del hijo es, por ello, una ley conocida y familiar, cuya aplicación al caso provoca costes conflictuales reducidos a los miembros de la familia.

17. En segundo término, la aplicación de la ley nacional del hijo evita discriminaciones por razón de sexo entre los progenitores del hijo, ya que el art. 9.4.I CC no toma en consideración, en ningún caso, ni la ley nacional del padre ni la ley nacional de la madre.

18. En tercer lugar, algunas familias de emigrantes extranjeros suelen cambiar con frecuencia de país de residencia, pues acuden al país donde se encuentra trabajo o donde habitan otros miembros de su familia. Con la conexión «nacionalidad del hijo», las relaciones entre padres e hijos siguen siempre sujetas a la misma ley "por encima de las fronteras». De ese modo, la ley que rige la filiación no cambia aunque el hijo cambie de país de residencia. Las ventajas operativas de la conexión nacionalidad del hijo en los casos de cambio de "país de mera residencia» son evidentes.

19. Esta conexión, sin embargo, y a pesar de que ha sido relegada a un segundo lugar en el escenario del art. 9.4.I CC, presenta ciertos inconvenientes.

En primer término, debe indicarse, sin ambages, que la conexión «nacionalidad del hijo» está anticuada. Hay que admitirlo. Cualquier resistencia a esta idea es inútil. La conexión «nacionalidad» (del hijo) refleja el tradicional, clásico y sempiterno "vértigo de la ley nacional», es decir, un desmesurado e injustificado ámbito de aplicación de la ley nacional de la persona a las cuestiones jurídicas que tienen que ver con su estado civil o su posición en el sistema jurídico. Desde un punto de vista de Derecho privado, la conexión nacionalidad del hijo es, en la mayor parte de los supuestos, una conexión ineficiente, una conexión que provoca costes conflictuales muy elevados a los particulares ${ }^{18}$. En efecto, la ley nacional del hijo o menor no es, necesariamente, la ley del país más vinculado al supuesto (= la ley que el hijo y la ley que sus presuntos padres esperan ver aplicada al supuesto). No se trata de evitar la aplicación de la ley nacional del hijo para provocar la aplicación de la ley del foro y evitar la aplicación de «Derecho extranjeros» que hay que probar en estrados. Se trata, más bien, de evitar la aplicación de la ley nacional del

18 RuIz Sutil, C., Filiación Hispano-Marroquí. La situación del nacido en España de progenitor marroquí, Pamplona, Thomson Reuters, 2011, p. 159. 
hijo para aplicar, en su lugar, la ley de la residencia habitual del mismo. En ocasiones, la nacionalidad puede reflejar un vínculo meramente formal, aparente, puramente formulario. Hay personas que mantienen su nacionalidad pero hace años que no regresan a su país o nunca lo van a hacer y no tienen relación alguna con dicho país. Por ello, la aplicación de la ley nacional del hijo puede comportar costes conflictuales muy elevados y totalmente innecesarios para los particulares implicados. Esta crítica es acertada en la mayor parte de los casos, y muy en particular en relación con hijos de inmigrantes extranjeros que viven en España plenamente integrados en la sociedad española. Por ello resulta más que justo que la nacionalidad se haya visto relegada a un papel subsidiario, puramente secundario, de modo que solo se aplica la ley nacional del hijo cuando este carece de residencia habitual o cuando la ley del país de su residencia habitual no permite determinar su filiación. En tales casos secundarios, la conexión cultural representada por la filiación del hijo puede ser más eficiente, porque, a falta de residencia habitual del hijo, la conexión que conduce al Derecho de más previsible aplicación por los particulares en los litigios de filiación suele ser el de la nacionalidad del hijo.

En segundo lugar, debe admitirse que, en el fondo, dejar la regulación de las materias concernientes al estatuto personal, como la filiación, en manos de la ley nacional de la persona refleja una cierta «directriz de soberanía». En realidad, se trata de una conexión decimonónica pensada para asegurar la aplicación de la ley de un Estado a los integrantes de su población y afianzar, así, la soberanía del Estado sobre dicha población. Es una conexión que sirvió, en el siglo XIX, para crear Estados nacientes, como Italia y Alemania. «Nacionalidad» deriva de «nación». Para esta conexión, lo importante no es tanto la «persona» cuanto la «nación». En verdad, la idea de que la aplicación de la ley nacional responde a la preservación de la «cultura de la persona» es una idea muy reciente. Una idea que no estaba presente en el art. 9 CC ni en 1889 ni en 1974. En la mente del legislador español, la persona y sus cualidades definitorias se rigen por su ley nacional porque de ese modo, el Estado del que es nacional la persona mantiene un «control jurídico» sobre su población. Se asegura, así, la base subjetiva del Estado. Esta perspectiva está hoy día superada. La soberanía del Estado no se ve perjudicada por el hecho de que las cuestiones relativas al estatuto personal de los particulares queden reguladas por una ley que no sea su ley nacional. En consecuencia, someter la filiación de las personas a la ley nacional del hijo no asegura la soberanía del Estado. El hecho de que el art. 9.4.I CC haya colocado a la «nacionalidad del hijo» en el segundo peldaño de la escalera conflictual manifiesta que el legislador español ha comprendido que la regulación conflictual de la filiación debe alejarse de la «directriz de soberanía estatal» y acercarse a los intereses de los particulares.

\subsection{Tercera conexión. Conexión judicial: ley española}

20. La ley sustantiva española se aplica en dos supuestos. En primer lugar, cuando el hijo carece de residencia habitual y carece también de nacio- 
nalidad. En este sentido, se trata de una «conexión de cierre», que permite concretar una ley estatal aplicable a la filiación cuando fallan las conexiones anteriores. En segundo lugar también encuentra aplicación cuando la ley del país de residencia habitual del hijo y la ley nacional del hijo no permitieran el establecimiento de la filiación de dicho hijo. En esta perspectiva se trata de una "conexión materialmente orientada», que persigue dar una nueva oportunidad conflictual al establecimiento de la filiación del hijo. Es la "conexión judicial». Se aplica la ley española porque es la ley del país al que pertenecen los tribunales españoles, los tribunales del país que conocen del asunto. La existencia de esta conexión debe explicarse desde tres puntos de vista.

21. En primer lugar, mediante una justificación conflictual. Cuando no existe un país en el que el hijo tiene su residencia habitual y dicho hijo no ostenta ninguna nacionalidad, resulta que falla la «conexión social» (= residencia habitual) y falla también la «conexión cultural» (= nacionalidad del hijo). El legislador activa entonces una «conexión judicial». Desde esta primera perspectiva, la conexión judicial es y opera como una auténtica "conexión de cierre». Es una conexión que se activa ante la imposibilidad de encontrar una conexión «social» o «cultural» que conduzca a una ley de aplicación suficientemente previsible para los sujetos implicados. Ello significa que esta conexión "Lex Fori» debe operar solo en relación con supuestos de filiación cuyos elementos se hallan espacialmente muy dispersos, supuestos frecuentemente anacionales: se trata de hijos sin nacionalidad que tampoco tienen residencia habitual en un concreto Estado. Son hipótesis de hijos que viven en contextos des-estatalizados. Será el caso, por ejemplo, de los refugiados o víctimas de guerras sin nacionalidad que vagan de un país a otro. Existe una conexión real y sustantiva entre el hijo y el litigio de filiación por un lado, y el Estado cuyos tribunales conocen del asunto (=Forum), por hipótesis, España. En efecto, debe subrayarse que un tribunal español solo se declarará internacionalmente competente en el caso de que concurra alguno de los foros de competencia judicial internacional recogidos en el art. 22 quater Ley Orgánica 6/1985, de 1 de julio, del Poder Judicial ${ }^{19}$. Por tanto, dicho foro debe haber justificado la competencia de los tribunales españoles para conocer del pleito de filiación. Visto que dicho foro aparece construido sobre el principio de "vinculación mínima suficiente» (art. $24 \mathrm{CE}$ de 6 de diciembre de $1978^{20}$, art. $6 \mathrm{CEDH}$ ), entonces existe una «conexión espacial real» entre España (= país cuya ley es aplicable como Lex Fori) y el litigio de filiación.

22. En segundo lugar, mediante una justificación materialmente orienta$d a$. El legislador español opta por esta conexión, en ciertos supuestos, porque considera que la ley de la residencia habitual del hijo y/o la ley nacional del mismo no proporcionan una solución justa al caso de filiación suscitado porque no permiten establecer la filiación del hijo. En tal hipótesis, el art. 9.4.I CC ordena aplicar la ley sustantiva española. En los casos en que la ley de

\footnotetext{
19 BOE núm. 157, de 2 de julio de 1985.

20 BOE núm. 311, de 29 de diciembre de 1978.
} 
la residencia habitual del hijo no es la ley española y en los que tampoco la ley nacional del mismo es la ley española, la conexión cobra sentido. La ley española puede ofrecer una "posibilidad de rescate», una last chance para acreditar la filiación del hijo. En los supuestos en los que la ley de la residencia habitual del hijo y/o la ley nacional del mismo sean la española pero dicha ley no permita establecer la filiación del hijo, la justificación de esta aplicación residual de la ley sustantiva española pierde fuerza valorativa. Se aplicará la ley española cuando antes ya se ha descartado aplicarla porque no permitía el establecimiento de la filiación. Puede afirmarse que, en estos últimos supuestos, la ley sustantiva española representa el último radical de justicia conflictual posible. Si no se ha podido establecer la filiación con arreglo a otras leyes de Estados más o menos vinculados con el caso, el legislador ofrece este último recurso para el establecimiento de la filiación que consiste en aplicar su propio Derecho, su Lex Materialis Fori.

23. En tercer lugar, a través de una justificación de seguridad jurídica última. El legislador español ordena la aplicación de la ley española y no de la ley del país con el que el supuesto presenta los vínculos más estrechos porque la conexión judicial ofrece estabilidad, una férrea seguridad jurídica de ordenación. No será preciso, ni para las partes ni para el juez, «contar y pesar los contactos espaciales del supuesto» con los distintos países para poder demostrar qué Estado presenta la vinculación más estrecha con el caso de filiación. La aplicación directa de la ley española es una solución directa, sencilla, y previsible que evita la laguna legal en el art. 9.4.I CC. Debe recordarse que también el legislador europeo ha optado, en otras materias, por esta «conexión judicial» como último peldaño de la escalera conflictual, por considerar que la misma ofrece un elevado grado de seguridad jurídica y evita especulaciones y litigios sobre los contactos del supuesto con los distintos países. Esta conexión de cierre y esta conexión materialmente orientada no exigen de los litigantes probar cuál es el país que presenta los vínculos más estrechos con la situación. Este enfoque es el que también ha seguido el art. 8.d) del Reglamento (UE) núm. 1259/2010, del Consejo, de 20 de diciembre, por el que se establece una cooperación reforzada en el ámbito de la ley aplicable al divorcio y a la separación judicial ${ }^{21}$ (RR-III), precepto que indica que la última conexión para fijar la ley aplicable al divorcio/separación judicial es la ley sustantiva del Estado miembro cuyos tribunales conocen del asunto.

24. Visto que la última conexión del precepto lleva a la aplicación de la ley material española, existe el peligro, muy real, de que los interesados no prueben el contenido y la vigencia de la ley extranjera correspondiente a la residencia habitual del hijo y de la ley nacional del hijo. Con ello, el tribunal competente, si sigue, como es de temer, la tesis dominante de la Sala $1 .^{\mathrm{a}}$ del Tribunal Supremo al respecto, siempre puede acudir a la ley material española. Este proceder es negativo: disminuye las posibilidades de reconocimiento de la sentencia española en el país de la residencia habitual y/o de la nacio-

21 DO núm. 343, de 29 de diciembre de 2010. 
nalidad del hijo y provoca un incremento de los costes conflictuales para el litigante que no tiene el deber jurídico de probar el Derecho extranjero, que será, con frecuencia, el demandado.

\section{LA ORIENTACIÓN MATERIAL DEL ART. 9.4.I CC}

\subsection{Contenido del Derecho aplicable y resultado de la aplicación del Derecho extranjero}

25. El art. 9.4.I CC es una norma de conflicto materialmente orientada por lo que se refiere al establecimiento de la filiación, similar a la que en otros países existe. Significa ello, expresa E. Bergamini, que la determinación de la ley aplicable al establecimiento de la filiación se hace con atención al contenido material de la ley aplicable y al resultado material al que conduce la aplicación práctica de dicho contenido en el caso concreto ${ }^{22}$. En efecto, el art. 9.4.I CC indica que si la ley de la residencia habitual del hijo no permite el establecimiento de la filiación, se aplicará entonces la ley nacional del hijo y que si esta tampoco lo permite, se aplicará entonces la ley sustantiva española. La norma exige «levantar el velo de la ley aplicable» (= para explorar su contenido) y valorar el resultado de la aplicación de dicha ley aplicable al caso concreto. Debe, pues, explorarse la solución material a la que conduce la aplicación de la ley designada por el art. 9.4.I CC. La ley designada por el precepto en sus dos primeras conexiones solo puede aplicarse si permite el establecimiento de la filiación del hijo. En caso contrario, eso es, si la ley del país de la residencia habitual del hijo no permite el establecimiento de la filiación, se pasará a la siguiente conexión, nacionalidad del hijo, en busca de una ley aplicable que sí permita el establecimiento de la filiación del hijo. Y si esta ley tampoco lo permite, se activará la tercera conexión, esto es la aplicación de la ley material española. Como explica A. v. Overbeck, este enfoque valorativo a través de puntos de conexión subsidiarios comporta un resultado similar al que podría haberse logrado mediante una norma de conflicto con puntos de conexión alternativos ${ }^{23}$. Esto es, habría sido similar el resultado si el art. 9.4.I CC hubiera indicado que el establecimiento de la filiación se rige por la ley de la residencia habitual del hijo o por la ley nacional del mismo.

26. El art. 9.4.I CC no es una norma de conflicto puramente localizadora y ciega a los resultados materiales a los que conduce. Es una norma con una

\footnotetext{
22 Bergamini, E., «Problemi di diritto internazionale privato collegati alla riforma dello status di figlio e questioni aperte», RDIPP, 2015, pp. 315-348; LoPES PEGNA, O., "Riforma della filiazione e diritto internazionale privato», $R D I, 2014$, pp. 394-418; Picone, P., «Le norme di conflitto alternative italiane in materia di filiazione», RDI, 1997, pp. 277-350; BudzIKIEwICZ, C., Materielle Statuseinheit und kollisionsrechtliche Statusverbesserung: zu der Rechtsstellung des ausserehelich geborenen Kindes unter Berücksichtigung der Folgen für das Kollisionsrecht der Legitimation, Tubinga, 2007.

${ }^{23}$ V. Overbeck, A., "L'intérêt de l'enfant et l'évolution de droit international privé de la filiation", $L i$ ber amicorum A. F. Schnitzer, Ginebra, 1979, pp. 361-380; id., «Essai sur la délimitation du domaine des conventions de droit international privé», en Ius et Lex. Festgabe Gutzwiller, Basel, 1959, pp. 325-349.
} 
carga valorativa material muy clara inyectada en la estructura de puntos de conexión. La ley aplicable depende, pues, no solo de los contactos espaciales del caso con los distintos países (= no depende solamente de que el supuesto esté más o menos vinculado a un país o a otro), sino del contenido de las leyes estatales en presencia y del resultado que se produce al aplicar tales leyes al caso en cuestión. La justicia conflictual está presente, pero está a su vez corregida y guiada, remarca S. Maya Bouyahia, por un radical de justicia sustantiva o material ${ }^{24}$. El carácter materialmente orientado del precepto exige analizarlo con suma atención. En especial, resulta necesario explorar en profundidad el significado de la expresión legal «ley que no permitiere el establecimiento de la filiación». La letra del art. 9.4.I CC señala, en efecto, que se debe rechazar la aplicación de ley designada por dicho precepto si dicha ley «no permitiere el establecimiento de la filiación». Se trata de una expresión muy general. El legislador no ha sido preciso y esa falta de precisión se detecta en diversos elementos de la norma.

27. En primer lugar, debe indicarse que el art. 9.4.I CC emite un juicio demoledor sobre la justicia de la ley aplicable designada por dicho precepto. $\mathrm{El}$ art. 9.4.I CC considera injusto, juris et de jure, que una ley, normalmente una ley extranjera, no permita establecer la filiación de un hijo. Por ello ordena descartar dicha ley y aplicar otra ley estatal distinta. Existe, pues una «competición entre leyes materiales», competición que gana la ley estatal que permita establecer la filiación del hijo. Las leyes que no permiten establecer la filiación del hijo son consideradas como leyes injustas, leyes odiosas. Es, sin duda, una herencia del pasado medieval, en el que los estatutarios consideraban que ciertas leyes (= «estatutos») de otras ciudades-Estado de la época no podían aplicarse fuera de su territorio debido a su contenido material radicalmente contrario al ideal de justicia vigente en aquel momento, representado, fundamentalmente, por el Derecho romano redescubierto en el norte de Italia en torno al año 1000. Esas leyes se denominaban «estatutos odiosos» (= statuta odiosa). Para el legislador español, un Derecho que no permite el establecimiento de la filiación del hijo es, sin más, un «estatuto odioso" y por ello no debe aplicarse en España aunque el mismo art. 9.4.I CC haya considerado justo que la filiación quede sujeta a dicha ley.

28. En la mayor parte de las ocasiones, esta norma de conflicto materialmente orientada produce una anticipación en la intervención del orden público internacional español. En efecto, el legislador español considera que una ley que no permite el establecimiento de la filiación del hijo es «injusta» desde el punto de vista jurídico español. Dicha ley produce consecuencias inaceptables para el Derecho español, es decir, consecuencias contrarias al orden público internacional español. Lo que este art. 9.4.I CC hace es adelantar, anticipar, anteponer la intervención del orden público internacional español en estos casos. De ese modo, no será preciso invocar el art. 12.3 CC

${ }^{24}$ Maya Bouyahia, S., La proximité en droit international privé de la famille, París, L'harmattan, 2015, pp. 240-255. 
para descartar la aplicación de una ley extranjera que no admite el establecimiento de la filiación. Basta con comprobar que sus normas no permiten, en el caso concreto, establecer la filiación del hijo. Ello es suficiente para rechazar la aplicación de tal ley y para pasar a la aplicación de la ley designada por el siguiente punto de conexión recogido en el art. 9.4.I CC.

29. Lo relevante es el resultado que se produce por la aplicación de la ley estatal reclamada por el art. 9.4.I CC en el caso concreto y no, simplemente, el contenido del Derecho aplicable designado por el precepto. En efecto, en otras ocasiones cuando el legislador ha querido evitar la aplicación de un Derecho estatal sin esperar a comprobar el resultado de la aplicación del mismo en el caso concreto, lo ha dejado bien claro. Es el caso, por ejemplo, del art. 10 del RR-III, que indica que « [c]uando la ley aplicable con arreglo a los artículos 5 u 8 no contemple el divorcio o no conceda a uno de los cónyuges, por motivos de sexo, igualdad de acceso al divorcio o a la separación judicial, se aplicará la ley del foro». Esta norma se refiere directamente al contenido legal. El enfoque metodológico del art. 9.4.I CC es diferente. En el contexto de este precepto, lo relevante es que el Derecho designado por el mismo no permita el establecimiento de la filiación en el caso del que se trate. Por tanto, no es suficiente un mero examen del «material jurídico» del Derecho estatal del que se trate para descartar la aplicación de dicho ordenamiento jurídico. Es preciso ir más allá, comprobar el impacto real de la aplicación de tal Derecho en el caso de especie.

30. El art. 9.4.I CC señala que si la ley de la residencia habitual del hijo no permitiere el establecimiento de la filiación, «se aplicará la ley nacional del hijo». La forma verbal empleada es claramente imperativa. En consecuencia, el juez español carece de todo margen de maniobra y/o de apreciación de oportunidad y tampoco puede modular la aplicación o no aplicación de la ley estatal designada con preferencia en virtud del art. 9.4.I CC. Por ello, si la ley de la residencia habitual no permite acreditar la filiación, el juez español está obligado por el texto legal a no aplicar tal ley y a aplicar, en su lugar, el Derecho del país de la nacionalidad del hijo. Y si la ley nacional del hijo tampoco permite acreditar la filiación, el juez español está obligado nuevamente a no aplicar tal ley y a dar aplicación al Derecho sustantivo español.

\subsection{La "paradoja conflictual circular»}

31. El art. 9.4.I CC no indica frente a qué específicas leyes estatales puede operar esta cláusula de rechazo de la aplicación de la ley que no permite el establecimiento de la filiación. El rechazo es indiscriminado, global y total, sin misericordia ni diferencia. El texto del art. 9.4.I CC no distingue: el precepto se aplica, por tanto, frente a toda ley estatal que conduzca a dicho resultado.

Este enfoque lo siguen también por otras normas de conflicto materialmente orientadas, como el art. 6 del Reglamento (CE) núm. 593/2008, del 
Parlamento Europeo y del Consejo, de 17 de junio, sobre la ley aplicable a las obligaciones contractuales (Roma I) ${ }^{25}$ (ley aplicable a los contratos internacionales de consumidores). Dicho precepto obliga al juez español a no aplicar la ley elegida por las partes si la ley del Estado de la residencia habitual del consumidor es más favorable a este de lo que le resulta la ley española. Pues bien, ello significa que el art. 9.4.I CC puede comportar la aplicación de la ley española como ley del país de la residencia habitual del hijo pero que si la ley española no permite el establecimiento de la filiación de dicho hijo, la ley española deberá descartarse y se procederá a aplicar la ley nacional del hijo. Si esta ley sí permite establecer su filiación, deberá aplicarse tal ley.

En estos casos, el resultado al que conduce el art. 9.4.I CC es, desde un punto de vista conflictual, paradójico: el legislador español que ha redactado este precepto considera que la ley sustantiva española es injusta y/o conduce a un resultado injusto. Por ello ordena descartarla y aplicar, en su lugar, la ley de otro país. Como es natural, el tribunal español competente siempre puede rizar el rizo y considerar que la ley nacional del hijo, que sí permite la determinación de la filiación del mismo, produce consecuencias contrarias a los principios fundamentales del Derecho español. En tal hipótesis, puede igualmente rechazar la aplicación de la ley nacional de hijo (= que en principio favorece la determinación de la filiación y por tanto, ex hypothesi, al hijo), mediante la excepción de orden público internacional (art. 12.3 CC). Este proceder le llevará a aplicar, en su lugar, la ley sustantiva española, que era lo que el legislador español trataba, precisamente, de evitar.

Se produce, pues, una "paradoja conflictual circular»: se ha rechazado la aplicación de la ley española porque no permite establecer la filiación, se aplica en su lugar otra ley estatal y visto que la aplicación de dicha ley conduce a resultados contrarios al orden público internacional español, se rechaza también la aplicación de esa ley estatal y se aplica, en su lugar, el Derecho español. Esta paradoja conflictual circular se produce porque el legislador no ha hilado fino al no precisar la causa, razón o motivo por la que la ley aplicable en primer término no permite establecer dicha filiación. Tampoco ha indicado el legislador español que no se aplicará la ley «extranjera» correspondiente a la residencia habitual del hijo o la ley extranjera correspondiente a la nacionalidad del mismo. El legislador español ha estimado, sin más, que debe rechazarse la aplicación de una ley estatal siempre que esta no permita establecer la filiación del hijo. La razón radica en que el legislador español ha considerado que el no establecimiento de la filiación siempre perjudica al hijo y que el establecimiento de dicha filiación siempre es un beneficio para el mismo. Pues bien, ello no es necesariamente así en todos los casos. La misma ley sustantiva española recoge ciertos supuestos en los que no debe establecerse la filiación del hijo porque ello le puede perjudicar. Frente a ello, el art. 9.4.I CC no ha tenido presente esta consideración y se presenta como un precepto redactado en términos excesivamente generales, terminantes y

25 DO L núm. 177, de 4 de julio de 2008. 
lapidarios: es un precepto que no ha cuidado los detalles. Esta complicación aplicativa generada por el texto del art. 9.4.I CC se hubiera evitado si el precepto hubiera puesto de manifiesto la razón última que debe presidir el descarte de una ley estatal, esto es, el favor filii. En este sentido, todo hubiera sido más lógico y sencillo si el precepto hubiera indicado que se aplicará la ley nacional del hijo y no la ley del país de la residencia del hijo cuando esta ley no permitiere el establecimiento de la filiación pero siempre que dicho establecimiento de la filiación fuera beneficioso para el hijo (véase el art. 125.I $\mathrm{CC}$ ). El caso se puede plantear en el supuesto de una filiación incestuosa. Si el hijo, nacional marroquí, reside habitualmente en España, la aplicable es la ley española, que, in casu, no permite el establecimiento de la filiación precisamente por ser incestuosa. De ese modo, el juez español estaría obligado a no aplicar el Derecho español y a aplicar, en su lugar, el Derecho marroquí. Si tal ordenamiento sí permite establecer la filiación incestuosa del hijo, el juez español podría estimar que ello vulnera el orden público internacional español (art. 12.3 CC), de modo que acabaría aplicando el Derecho material español, que no permite el establecimiento de la filiación. Y que era lo que el art. 9.4.I CC quería evitar. La vida está llena de paradojas y la norma de conflicto (materialmente orientada) no va a ser menos.

\subsection{Motivos que impiden establecer la filiación}

32. El art. 9.4.I CC no concreta cuál es el motivo, causa o razón recogido en una ley designada por tal norma y por el que no es posible, en el marco de dicha ley, establecer la filiación del hijo. Ante la duda, dos grandes líneas interpretativas surgen.

33. Una primera línea apuesta por una interpretación restrictiva del inciso legal. Puede sostenerse que el inciso legal que indica que «si esta ley no permitiere el establecimiento de la filiación» presenta un significado de «rescate para casos extremos». Se trataría de activar el inciso citado y la orientación material del art. 9.4.I CC solo si el hijo no tiene ninguna filiación ni puede tenerla con arreglo a la ley designada por el art. 9.4.I CC. Con dicha lectura, el inciso mencionado serviría para «dar un padre o madre» a quien no lo tiene con arreglo a dicha ley ( = rescatar la filiación en casos en los que el hijo carece totalmente de ella). Esta interpretación parece muy razonable. No obstante, la dicción general, amplia, sin matices, la letra hierática del precepto no parece respaldar esta interpretación restrictiva, válida solo para casos límite. El legislador español, en efecto, ha querido descartar la aplicación de una ley que no permite, in casu, el establecimiento de una filiación cuya existencia legal se debate ante los tribunales españoles. Así, si se ejercita la acción de filiación extramatrimonial contra el padre biológico, español y con residencia habitual en España, de un bebé sirio nacido en Damasco de madre siria, y la ley siria, aplicable al caso ex art. 9.4.I CC (conexión primera), no permite acreditar el establecimiento de la filiación por el exclusivo motivo de que esta es extramatrimonial, el art. 9.4.I CC ordena reaccionar contra la 
aplicación de la ley siria aunque el hijo tenga ya una madre legalmente acreditada con arreglo al Derecho sirio. El art. 9.4.I CC reacciona porque el ordenamiento jurídico sirio no permite, in casu, establecer la filiación paterna aunque el hijo tenga acreditada legalmente su filiación materna.

34. Una segunda lectura interpretativa conduce a una comprensión amplia del inciso controvertido. El art. 9.4.I CC presenta, es cierto, una redacción muy amplia. Contiene una afirmación general expresada sin restricciones. Por ello debe aplicarse sin recortar su alcance literal. La intención del legislador español es la de reaccionar, a través de una norma de conflicto materialmente orientada, contra la aplicación de una ley que, en un caso concreto y por la causa que fuere, no permite determinar legalmente una concreta filiación en relación con un hijo en particular.

35. Con arreglo a esta segunda lectura interpretativa del art. 9.4.I CC, conduce a activar la orientación material de esta norma de conflicto en los siguientes litigios:

$1 .^{\circ}$ Litigios en los que se trata de establecer una filiación, ya tenga el hijo acreditada una filiación anteriormente o no la tenga y ya se trate de establecer ex novo una filiación o de impugnar una filiación previamente existente para fijar una nueva filiación. No es aplicable, por tanto, este inciso, a los casos en los que se ejercita una acción de impugnación pura de filiación sin que se pretenda establecer ninguna otra filiación en concreto.

2. ${ }^{\circ}$ Litigios en los que queda probada la imposibilidad de establecer la filiación de un hijo en el contexto de la ley aplicable ex art. 9.4.I CC, sea cual sea la causa de dicha imposibilidad. Las causas, fundamentos, razones o motivos por los que puede no ser posible establecer la filiación según la ley estatal aplicable son de diversos tipos:

a) Causas ligadas a la prueba de la filiación. Ciertas leyes consideran ilegal o inadmisible practicar ciertas pruebas de la filiación, como las pruebas biológicas.

b) Causas relativas al transcurso del tiempo y/o prescripción de acciones de filiación. Entre tales causas, cabe citar: $a$ ) rechazo de la filiación matrimonial por haber transcurrido el plazo legal para hacerla constar, y $b$ ) prescripción de la acción para determinar la filiación.

c) Causas relativas a la legitimación activa o pasiva para declarar la filiación. Estas causas concurren cuando la ley aplicable niega al presunto padre o madre la posibilidad de accionar para acreditar la filiación o impiden establecer la filiación en relación con un determinado hijo en particular.

d) Causas relativas al título de la filiación. Los títulos para acreditar la filiación varían de Estado a Estado. Una ley estatal concreta puede rechazar in casu el establecimiento de la filiación porque no admite un concreto título de filiación. En particular, pueden citarse: a) negativa legal a un reconocimiento de la filiación realizado en documento público, privado o ante funcionario registral por cualquier causa de fondo o de forma o porque no se admite el mismo reconocimiento de la filiación como título de la misma (= falta de 
capacidad del progenitor, necesidad de consentimiento del hijo, el hijo ha fallecido, necesidad de intervención judicial o registral, etc.); b) negativa legal a admitir la filiación del hijo por declaración realizada por una persona en el momento de la inscripción registral del nacimiento del hijo; c) negativa legal a admitir la filiación del hijo por resolución recaída tras un expediente registral; d) negativa legal a admitir la filiación del hijo por sentencia judicial; e) negativa legal admitir la filiación del hijo porque no existe, en la ley aplicable, un sistema de presunciones aplicable a la filiación matrimonial, y f) negación de la posesión de estado como título de filiación.

e) Causas relativas al tipo de filiación. Las distintas leyes estatales prohíben, dificultan o impiden establecer ciertos tipos de filiación por los motivos más diversos. Algunos Derechos, en efecto, indican que no es posible establecer ciertos tipos de filiación: a) negación total de la posibilidad de establecer un concreto tipo de filiación, como la extramatrimonial o la filiación en favor de padres comitentes en relación con un nacido de madre subrogada; $b$ ) imposibilidad total o parcial de establecer una filiación en casos específicos en los que puede perjudicar al hijo, como la filiación llamada incestuosa (art. 125 $\mathrm{CC}), \mathrm{y}$ c) imposibilidad de establecer la filiación por motivos discriminatorios basados en condiciones de raza, religión o sexo de los padres o del hijo.

\subsection{Análisis crítico de la orientación material del art. 9.4.I CC}

36. La orientación material del art. 9.4.I CC exige un análisis crítico especialmente cuidado y ponderado en torno a diferentes aspectos de la norma.

37. En primer lugar, y aunque suene kantiano, debe subrayarse que la intención es buena. Se trata de introducir lo que antes no existía en el texto del art. 9.4.I CC: el favor filii en la determinación de la filiación. El legislador español ha diseñado una norma de conflicto materialmente orientada que persigue aumentar las posibilidades de acreditación de la filiación del hijo. Puede, por ello, afirmarse, que la intención del legislador es, como punto de partida y desde un punto de vista constitucional y apoyado también en la normativa legal internacional vigente para España que recoge, defiende y promociona los derechos humanos, una buena intención. Y lo es porque, en general, en la mayor parte de los casos, la determinación de la filiación de una persona es beneficiosa para la misma. En efecto, ello proporciona al hijo una identidad, un nombre y apellidos, la posibilidad de tener derechos sucesorios, de adquirir una nacionalidad estatal determinada y le concede también un derecho de alimentos en relación con sus parientes. Del mismo modo, también ello permite que el hijo, si es menor, disponga de mecanismos legales de protección específicos para los hijos menores, como la patria potestad del Derecho español. Por tanto, potenciar la posibilidad de acreditación de la filiación de un hijo parece correcto desde un punto de vista de la posición del hijo en el sistema legal y de la protección jurídica del hijo, pues en la inmensa mayoría de las ocasiones, es mejor para el hijo, por los motivos examinados, tener unos padres por naturaleza determinados legalmente, que no tenerlos. 
En este sentido, el «hecho» de contar con una norma de conflicto materialmente orientada en el art. 9.4.I CC queda superado por el «significado de tal hecho». Desde una perspectiva estrictamente fenomenológica, resulta muy importante poner de relieve que, en ciertos sectores jurídicos y en especial en el relativo a la protección de los hijos y de los menores, el legislador español toma partido. No es neutral. Se posiciona. Resulta conveniente captar esta idea, porque se trata de la esencia misma del art. 9.4.I CC. Los aspectos técnicos del art. 9.4.I CC relativos a la puesta en marcha de esa esencia valorativa constituyen, en verdad, realidades puramente contingentes. El legislador español puede haber errado en la traducción técnico-jurídica de esa idea esencial, puede no haber sido todo lo preciso que era deseable. Sin embargo, eso no es tan importante como es el núcleo valorativo del art. 9.4.I CC, su intención axiológica. Esa esencia misma del precepto (= la realidad necesaria del mismo) radica, como se ha señalado, en la idea de que, a la hora de precisar la ley aplicable a la filiación, no basta con «contar y pesar» los contactos del supuesto con los distintos Estados. Es imprescindible, por el contrario, tener presentes, con la mayor intensidad posible, los intereses del hijo y por tanto, seleccionar la ley estatal aplicable que más convenga al hijo a la hora de establecer su filiación legal. El jurista debe activar su «intuición eidética» para percibir la realidad última, esto es, lo esencial, el significado profundo del art. 9.4.I CC. Ello resulta extraordinariamente conveniente, provechoso y apropiado para interpretar de modo correcto el entero art. 9.4.I CC. Por otro lado, observa S. Vrellis, ello coadyuva a profundizar en la justicia material realizada por las normas de conflicto en defensa del favor filii ${ }^{26}$.

38. En segundo lugar, también es verdad que the road to hell is paved with good intentions. En efecto, el modo que ha elegido el legislador para realizar dicha política de favor filii en la determinación de la filiación no es ya tan positivo. Por ello, la orientación material del art. 9.4.I CC puede y debe ser objeto de ciertas críticas a desarrollar no desde un punto de vista valorativo, sino desde una perspectiva exclusivamente técnica y ajustadamente conflictual.

39. En este plano crítico, debe indicarse, en primer término, que, para comenzar, la determinación de la filiación del hijo no es siempre un beneficio para este. No siempre la acreditación de la filiación de un hijo respecto de un concreto padre constituye un beneficio para dicho hijo incluso desde la perspectiva del Derecho español. Dos ejemplos serán suficientes: i) en el caso de que una ley extranjera permita la acreditación de la filiación de un hijo respecto de su abuelo (= filiación respecto de pariente en línea recta), dicha filiación puede perjudicar al hijo (art. $125 \mathrm{CC}$ ). El mismo legislador español entiende que la acreditación de dicha filiación no es conveniente para el hijo y por eso mismo niega dicha posibilidad con carácter general, y solo la permite «previa autorización judicial que se otorgará, con audiencia del Ministerio

26 VRELlis, S., "Conflit ou coordination de valeurs en droit international privé. A la recherche de la justice», $R C A D I$, vol. 328,2007 , pp. 175-486. 
Fiscal, cuando convenga al menor o incapaz» y admite, también, que el hijo, alcanzada su plena capacidad, pueda mediante declaración auténtica invalidar la determinación de su filiación si no la hubiere consentido; ii) la filiación del nacido como consecuencia de un contrato de gestación por sustitución corresponde a la mujer que ha dado a luz y no a los sujetos que han contratado a dicha mujer para que geste al hijo. Ciertas leyes extranjeras establecen que la filiación corresponde a tales sujetos (= padres comitentes/intended parents), mientras que el Derecho español considera que no es conveniente que se establezca una filiación del hijo en relación con dichos partes comitentes (art. 10.2 de la Ley 14/2006, de 26 de mayo, sobre técnicas de reproducción humana asistida $)^{27}$. En suma, hay numerosos supuestos en los que la ley española no permite el establecimiento de la filiación, incluso en favor de los progenitores biológicos.

Frente a lo anterior, la dicción literal del art. 9.4.I CC es excesivamente genérica y no distingue. Para el legislador español que ha redactado el art. 9.4.I $\mathrm{CC}$, si la ley de la residencia habitual del hijo, incluso cuando sea la española, no permite el establecimiento de la filiación, dicha ley se descartará y en su lugar se aplicará la ley nacional del hijo. El precepto no diferencia matices y ahí, en su carácter rígido y lapidario, radica su debilidad: no se especifica la causa por la que la ley del país de residencia habitual del hijo no permite el establecimiento de la filiación. El precepto no está atento a los detalles. En consecuencia la paradoja está servida. Así, por ejemplo, si la ley de la residencia habitual del hijo ucraniano, por ejemplo la ley española, no permite establecer la filiación de este respecto de sus padres contratantes porque, por ejemplo, ha nacido de "madre contratada», se aplicará la ley nacional del hijo y si el hijo es, como se ha indicado, ucraniano, entonces se aplicará la ley ucraniana porque esta sí permite establecer la filiación en favor de los padres comitentes. Con ello se alcanza un resultado que la ley imperativa española estima contrario a Derecho. En otros supuestos puede ser incluso peor. Si la ley de la residencia habitual del hijo, por ejemplo la ley española, no permite establecer la filiación de este respecto de sus progenitores porque estos son hermanos, se aplicará la ley nacional del hijo y si el hijo es iraní, y la ley de este país permitiera establecer esta filiación incestuosa, entonces se debería aplicar la ley iraní. Con ello, de nuevo, se alcanza un resultado que la ley española considera radicalmente contrario a Derecho y que puede objetivamente perjudicar al menor. Ello obligará, como antes se ha adelantado, a activar el orden público internacional español (art. 12.3 CC) para descartar la aplicación de la ley iraní, de modo que deberá aplicarse la ley sustantiva española (= tercera y última conexión del art. 9.4.I CC), cuya aplicación ya fue descartada por el mismo art. 9.4.I CC. Esto sucede porque el precepto no opera como debe operar un buen jurista, esto es, diferenciando y coloreando matices y no da poder al juez para decidir si el no establecimiento de la filiación derivado de la aplicación de una concreta ley estatal es o no es beneficiosa para el hijo. Es un precepto que cree más en la ley que en los jueces,

27 BOE núm. 126, de 27 de mayo de 2006. 
cree más en la rigidez de la norma legal escrita que en los detalles de los casos concretos y en las cláusulas de flexibilización. Por eso es criticable. Porque este enfoque puede llevar a paradojas legales que pueden perjudicar al mismo menor al que se desea beneficiar.

40. Todavía en este plano crítico, debe indicarse, en segundo término, que el punto de partida del art. 9.4.I CC es muy claro. Para el precepto existen Derechos estatales justos (= los que permiten establecer la filiación del hijo) y Derechos estatales injustos (= los que no lo permiten). Como es natural, este juicio sobre la justicia de las leyes extranjeras depende del punto de vista que se adopte. Desde la perspectiva del legislador español, es evidente, las leyes favorables al establecimiento de la filiación son «justas» y las que no posibilitan dicho establecimiento son «injustas». Ahora bien, desde la perspectiva de un legislador extranjero cuya ley no permite el establecimiento de la filiación, resultará que la ley española, al permitir el establecimiento de la filiación, es «injusta». Para un jurista iraquí, es muy posible que el establecimiento de la filiación por naturaleza de un bebé en relación con dos mujeres sea una solución aberrante, anti-natura y profundamente injusta, mientras que para el legislador español constituye una solución adecuada, proporcional, conveniente y, en suma, justa. En realidad, si se adopta un punto de vista abstracto y general, alejado de un concreto ordenamiento jurídico, no existen Derechos estatales «más justos» que otros. Desde este enfoque, comenta H. GaudemetTallon, todos los Derechos estatales están situados en una «posición de igualdad», de modo que aplicar un Derecho estatal porque es «más justo» que otro no es adecuado ni conveniente ${ }^{28}$. Cada legislador estatal elabora las normas que considera justas para su sociedad. Todo Estado considera y cree que sus leyes son «justas». Lo que resulta, en realidad, injusto, es aplicar un Derecho estatal a situaciones privadas internacionales no conectadas con dicho país. $\mathrm{Y}$ es injusto porque genera elevados costes para los particulares y porque conduce a aplicar la ley de un Estado a supuestos no vinculados con la sociedad de dicho Estado.

41. También desde una perspectiva crítica, en tercer lugar debe subrayarse que el art. 9.4.I CC, como norma de conflicto materialmente orientada que es, traduce la línea política de un concreto Estado, en este caso, la línea española de política jurídica en el sector de la filiación. Desde ese momento, esta norma dificulta la internacionalización de las normas de DIPr, es decir, la elaboración de normas de conflicto comunes a distintos países. Si la determinación de la filiación del hijo constituye una política firme del legislador español pero no de otros Estados, la unificación de las normas de conflicto en el sector de la filiación entre ambos Estados resulta prácticamente imposible.

42. Desde un punto de vista crítico, en cuarto término, no puede ignorarse que el art. 9.4.I CC aumenta el riesgo de Forum Shopping y el nivel de inseguridad jurídica. No será extraño que las partes jueguen al Forum

${ }^{28}$ Gaudemet-Tallon, H., «Le pluralisme en droit international privé: richesses et faiblesses (Le funambule et l'arc-en-ciel), cours général», RCADI, 2006, pp. 1-488, esp. p. 297. 
Shopping y corran con entusiasmo a litigar ante la jurisdicción que mejores ventajas ofrezca a sus intereses desde el punto de vista de la ley reguladora del fondo de la filiación.

\section{REFLEXIÓN FINAL}

43. El nuevo texto del art. 9.4.I CC contiene numerosos elementos positivos que conviene resaltar:

1. $\left.{ }^{\circ}\right)$ La preferencia aplicativa dada a la conexión residencia habitual sobre la conexión nacionalidad, plenamente acertada, coloca al sistema español en perfecta sintonía con la tendencia más moderna seguida por el DIPr de la UE. En los tiempos actuales, esta conexión es la adecuada visto el carácter líquido de la sociedad actual y los movimientos internacionales de las personas. Conduce a una ley previsible y eficiente para las partes y para terceros y permite a los Estados llevar a cabo una organización efectiva y eficiente de su sociedad en lo relativo a la filiación.

2..$^{\circ}$ La nacionalidad ha entrado en su definitiva fase crepuscular como punto de conexión principal incluso en las materias relativas al tradicional «estatuto personal» y es justo que así sea. El reinado de la ley nacional toca a su fin y demasiado largo ha sido.

3. ${ }^{\circ}$ La ausencia de autonomía de la voluntad conflictual en el precepto es lógica. Se trata de una materia de Derecho imperativo, de Derecho privado institucional, esencial para el buen funcionamiento de la sociedad. Por esa razón, no debe permitirse que las partes elijan el Derecho aplicable a la filiación.

4. ${ }^{\circ}$ ) Por otra parte, y a pesar de ciertos defectos técnicos del art. 9.4.I $\mathrm{CC}$, el carácter materialmente orientado de las conexiones en lo que afecta a la determinación de la filiación constituye un acierto axiológico del legislador. En una materia particularmente sensible como la filiación, atrás quedan puntos de conexión ciegos que concretaban el Derecho aplicable sin tener en cuenta valores materiales. Un Derecho internacional privado del siglo XXI exige contar con normas, como el actual art. 9.4.I CC, comprometidas con valores sustantivos constitucionales y con los derechos humanos. Bienvenido, pues, este nuevo art. 9.4.I CC.

\section{RESUMEN}

\section{LEY APLICABLE A LA FILIACIÓN POR NATURALEZA: DE LA LEY NACIONAL A LA LEY DE LA RESIDENCIA HABITUAL DEL HIJO}

Este trabajo examina varios aspectos del art. 9.4.I CC en su redacción dada por la Ley $26 / 2015$, de 28 de julio, de modificación del sistema de protección a la infancia y a la adolescencia. El análisis permite descubrir que esta norma de conflicto ha optado por dar preferencia a la residencia habitual sobre la nacionalidad del hijo y que dicha opción de política jurídica es correcta desde un punto de vista constitucional y desde una perspectiva de eficiencia. La residencia habitual conduce a aplicar una ley que asegura una buena ad- 
ministración de la justicia y unos costes conflictuales reducidos para las partes. El trabajo también explora el carácter materialmente orientado del art. 9.4 CC a la hora de fijar la ley aplicable a la determinación de la filiación.

Palabras clave: filiación, norma de conflicto materialmente orientada, prueba de la filiación, residencia habitual, nacionalidad.

\section{ABSTRACT \\ ON THE LAW APPLICABLE TO BIOLOGICAL PARENTAGE: FROM THE LAW OF THE CHILD'S NATIONALITY TO THE LAW OF THE HABITUAL RESIDENCE}

This study deals with different aspects of Article 9.4 first paragraph of the Spanish civil Code after the new wording given by Act 26/2015, of July 28th, modifying the system of protection of children and adolescence. The analysis allows to discover that this conflict rule has given preference to the habitual residence of the son on his nationality as a connecting factor. This criterion is correct from a constitutional standpoint and from an efficiency perspective. Habitual residence leads to apply a law that ensures the sound administration of justice and reduced costs for the parties involved. The work also explores the materially oriented character of the above mentioned Article 9.4 when setting the law applicable to the determination of parentage.

Keywords: filiation, materially oriented conflict rule, habitual residence of the son, nationality of the son. 